\title{
A FORMAÇÃO CONTINUADA COMO FATOR DE INTENSIFICAÇÃO DO TRABALHO
}

\author{
Aline Gabriele Pereira \\ Universidade Federal de Minas Gerais
}

Fernando Selmar Rocha Fidalgo

Universidade Federal de Minas Gerais

\section{Resumo}

O presente artigo propõe uma reflexão acerca da inserção da formação continuada no ideário e no cotidiano dos trabalhadores, cada vez mais frequente nos dias atuais. Para tanto são discutidos conceitos como os de tempo de trabalho e tempo livre/de não trabalho, bem como de intensificação do trabalho; com base em pesquisa de 2012, realizada com gestores participantes do Curso de Especialização em Gestão escolar, parte do Programa Nacional Escola de Gestores da Educação Básica, na qual foram analisados os tempos e espaços desses sujeitos em formação continuada através da educação a distância. Pôde-se constatar que a realização da formação continuada se concentrou quase completamente no tempo livre/de não trabalho dos gestores participantes, sendo realizada em seus domicílios, durante as noites e finais de semana e caracterizando-se, portanto, como um fator de intensificação através do prolongamento da jornada de trabalho.

Palavras-chave: Formação continuada; intensificação do trabalho; tempo de trabalho/tempo livre. 


\title{
CONTINUING EDUCATION AS AN INTENSIFYING FACTOR OF WORK
}

\begin{abstract}
This paper proposes a reflection on the insertion of continuing education in ideology and daily life of workers, increasingly common nowadays. For this are discussed concepts such as work time and free time/not work as well as the intensification of labor. Based on 2012 survey, conducted with school managers participating in the Specialization Course in School Management, part of the National School Program Managers of Basic Education, in which were analyzed the time and space of these students of continuing education through distance education. It was noted that the fulfillment of continuing education focused almost entirely on the participants' free time/not work, being held at their homes during evenings and weekends, and therefore characterized as a factor of intensification of labor through longer working hours.
\end{abstract}

Keywords: Continuing education; intensification of labor; work time/free time. 


\section{Introdução}

Apesar de ter se tornado cada vez mais recorrente no discurso e nos estudos educacionais, o conceito de formação continuada não está bem definido. De acordo com Gatti (2008), as utilizações do conceito se dividem, em sua maioria, em dois grupos: o primeiro refere-se ao termo para tratar exclusivamente de cursos formais, realizados após a graduação e a inserção no mercado de trabalho; já o segundo grupo amplia e generaliza sua utilização, relacionando o termo a qualquer experiência ou atividade que possa contribuir para o desempenho profissional, dentro ou fora do local de trabalho. Entretanto, a autora argumenta que, mais importante do que definir um conceito fechado, é constatar que tais atividades vêm crescendo rapidamente pelo Brasil (em especial nas regiões Sul e Sudeste), nem sempre acompanhadas do credenciamento e reconhecimento que seriam necessários. Importante também é perceber que essa multiplicação não acontece sem motivo, vem em resposta às constantes mudanças nas quais a sociedade atual está inserida.

As mudanças que tomaram forma na educação no Brasil nas últimas décadas são reflexo de mudanças mais profundas, de dimensão global, resultado de mais uma transformação na forma de organização capitalista, que passou do regime de acumulação taylorista/fordista para o que Harvey (2012) chama de regime de acumulação flexível, também conhecido como toyotismo.

Segundo o autor, o regime de acumulação flexível se desenvolve como que em completa oposição ao regime de produção taylorista/fordista, famoso por sua rigidez e controle e pelas sucessivas crises de superacumulação. $O$ novo regime se caracteriza pela flexibilidade não só na produção que, seguindo "just in time" a demanda do mercado evita o problema da superacumulação; mas

$1 \quad{ }^{7} \mathrm{Na}$ hora exata.

Olh@res, Guarulhos, v. 2, n. 2, p. 135-153. Dezembro, 2014. 
também dos padrões de consumo, do mercado e da organização dos processos de trabalho. Esse movimento cria uma sociedade onde interesses, gostos e necessidades mudam com uma frequência diária, refletindo uma indústria acompanhada por maciças inovações tecnológicas, onde mais do que nunca "o conhecimento da última técnica, do mais novo produto, da mais recente descoberta científica, implica a possibilidade de alcançar uma importante vantagem competitiva" (HARVEY, 2012, p. 151).

Em consequência, substitui-se (muitas vezes literalmente) o trabalhador especializado numa única e repetitiva tarefa, por um trabalhador multifuncional, capaz de operar mais de uma máquina ao mesmo tempo e em interminável processo de aperfeiçoamento para lidar com as constantes transformações tecnológicas.

Segundo Antunes (2009), para alguns autores essas mudanças significam uma melhoria nos processos de trabalho, por possibilitar ao trabalhador melhor qualificação e, através da maior participação no todo do processo produtivo e do desenvolvimento da polivalência, uma possível superação das contradições básicas do capitalismo conhecidas pela alienação do trabalho, também chamada pelo autor de "estranhamento". Ele, porém, explica que o regime de acumulação flexível gera, ao contrário, um processo de intensificação do trabalho e da crescente utilização de trabalho chamado precarizado (terceirizado, subcontratado, de tempo parcial, etc.).

Em concordância, Harvey (2012) discute que o por ele chamado trabalho flexível, apesar de algumas vezes ser mutuamente benéfico, em sua maioria não pode absolutamente ser considerado positivo quando diminui os níveis salariais, os direitos trabalhistas e a segurança no emprego. Além disso, o enfraquecimento do poder sindical que tomou forma ainda no período do taylorismo/fordismo, acrescido do aumento do desemprego estrutural que parece ser implicação do novo regime de produção, fazem com que, apesar da necessidade rápida e constante de 
destruição e reconstrução de habilidades do trabalhador, ele permaneça com ganhos modestos ou até mesmo inexistentes de salários.

Nesse contexto é que se torna fundamental o desenvolvimento de novas competências, valores e habilidades para lidar com as mudanças na sociedade; a formação passou a ser vista como um processo de adaptação constante às mudanças nos conhecimentos e tecnologias.

Seguindo a mesma linha, Kenski (1998) discute que as novas demandas de produção industrial, em função do constante avanço tecnológico provocaram uma mudança profunda na noção de formação que se tinha tradicionalmente, quando se tinha um tempo determinado de "ir à escola" depois do qual a pessoa podia se considerar formada e, a partir daí, iniciar-se em alguma profissão. Em nossa sociedade

[...] as velozes transformações tecnológicas da atualidade impõem novos ritmos e dimensões à tarefa de ensinar e aprender. É preciso que se esteja em permanente estado de aprendizagem e de adaptação ao novo. Não existe mais a possibilidade de se considerar a pessoa totalmente formada, independentemente do grau de escolarização alcançado (KENSKI, 1998, p. 60).

Porém, é importante ressaltar a forma como esse ideário de formação continuada vem se fortalecendo na cultura atual. Relacionada a conceitos como o de empregabilidade (ALBERTO, 2005) ou competência (ROSENFIELD; NARDI, 2006), essas novas configurações atribuem ao próprio trabalhador a responsabilidade pela adaptação às novidades, por sua remuneração e até mesmo pela manutenção de seu posto de trabalho; assim como recai sobre ele também a culpa quando não consegue se adaptar às novidades, não alcança a remuneração desejada ou não consegue manter seu posto de trabalho.

Segundo Fidalgo e Aranha (2010), isso incita um clima de competição e individualização, no qual o trabalhador é convencido de que suas competências individuais é que legitimam suas condições de trabalho e salariais. Isso segundo a autora vem provocando uma Olh@res, Guarulhos, v. 2, n. 2, p. 135-153. Dezembro, 2014. 
reestruturação educacional, um aumento inédito da procura por formação inicial e continuada.

Dessa forma, apesar da indiscutível necessidade de formação continuada do trabalhador, atualmente, é necessário refletir sobre a forma como esta tem se inserido em sua vida, e quais são suas implicações no campo laboral e pessoal.

\section{Tempo de trabalho e tempo livre}

Segundo Dal Rosso (2011, p. 307) o conceito de Tempo de Trabalho pode ser compreendido através de, pelo menos, três dimensões: Duração, ou seja, o tempo compreendido entre o início e o término do trabalho, mais conhecido como jornada; Distribuição, que representa quando esse trabalho é executado, a "estabilidade ou flexibilidade dos horários, o trabalho em turnos, a compensação de horas, os contratos com duração anual e distribuição flexível e a idade para início e fim da vida ativa são aspectos relevantes da distribuição"; por fim, a Dimensão da intensidade, que corresponderia ao esforço empregado na realização da tarefa, seja ele físico, intelectual ou emocional. Dessa forma, o autor demonstra que a ideia de tempo de trabalho se opõe à de tempo de não-trabalho, que representaria o tempo localizado fora da jornada de trabalho, como os tempos de descanso, lazer e atividades criativas.

Entretanto, é importante frisar que o fato de ser o tempo de nãotrabalho localizado fora do tempo oficial de trabalho, isso não significa que um esteja desvinculado do outro, já que, como bem ressalta o autor, essa separação entre os dois se torna cada vez mais tênue em nossa sociedade atual.

Por fim, Dal Rosso (2011) argumenta que tempo de não-trabalho se diferencia da noção de tempo livre, sendo que o segundo se estenderia para além da definição de tempo de não-trabalho (que também pode incluir o tempo de desemprego), alcançando uma 
dimensão de tempo regido pela lei da liberdade, que representaria o objetivo da luta dos trabalhadores.

Já Antunes (2009), apesar de não adotar a diferenciação dos termos e optar pelo uso do conceito "Tempo Livre” para designar, inclusive, o tempo que o trabalhador ganha com a redução da jornada de trabalho, deixa clara sua opinião ao utilizar o termo entre aspas para polemizar as repercussões do mundo do trabalho sobre a vida do trabalhador fora do trabalho, argumentando que na sociedade contemporânea o capital domina a vida do trabalhador por inteiro, levando-o a gastar seu "tempo livre" no consumo em shoppings e turismo; utilizando-o também, para adquirir a tão divulgada empregabilidade.

Essa lógica que tanto se expandiu nos dias atuais, é sentida também pelo educador que busca na formação continuada melhorias salariais, e em suas condições de trabalho, tão precarizadas; algo que pôde ser visto em pesquisa realizada no ano de 2012, em que foram aplicados questionários em 260 egressos do Curso de Especialização em Gestão Escolar, ofertado pela UFMG como parte do Programa Nacional Escola de Gestores da Educação Básica, coordenado pela Secretaria de Educação Básica (SEB/MEC), bem como em entrevistas realizadas com 15 deles.

A pesquisa buscou analisar os tempos e espaços utilizados por esses sujeitos para a realização da formação continuada em gestão. Nos questionários aplicados e entrevistas realizadas foram respondidas questões que possibilitaram desvelar a rotina de formação dos participantes do curso (frequência de dias e horários utilizados na realização das tarefas do curso); desafios e facilidades da educação a distância; carga horária de trabalho na escola; como percebiam a gestão escolar, entre outras. Assim, foi possível perceber a forma como, discretamente, a formação continuada torna-se um mecanismo de intensificação do trabalho, invadindo os tempos e espaços de descanso e Olh@res, Guarulhos, v. 2, n. 2, p. 135-153. Dezembro, 2014. 
lazer dos gestores/professores participantes, direta e indiretamente (PEREIRA; FIDALGO, 2013).

$\mathrm{Na}$ referida pesquisa, pôde-se constatar as nuances nos tempos e espaços dos gestores participantes do Curso de Especialização em Gestão Escolar, que variam a depender da posse ou não do computador e da internet em casa; da pouca ou muita habilidade para lidar com o computador; da carga horária de trabalho; e do fato de serem homens ou mulheres.

Entretanto, é importante lembrar, que a despeito dessas diferenças e influências, quando analisados os dados gerais das respostas dos egressos do curso, fica claro que sua grande maioria $(81 \%)$ raramente ou nunca realizava as atividades do curso de segunda a sexta-feira durante o dia, dividindo seu tempo entre as noites e os finais de semana; além disso, 96\% deles realizavam as atividades do curso sempre ou frequentemente em casa, uma média de 9,5\% apresentada para as mesmas opções nos demais locais.

Dessa maneira, tornam-se fundamentais as perguntas: Onde se inseriu a formação continuada na vida e no cotidiano desses gestores? Em seus tempos de trabalho ou em seu tempo de não-trabalho/"livre”? E o que representa um curso de especialização na vida de um trabalhador, trabalho ou não-trabalho?

\section{Intensificação do trabalho e formação continuada}

Como dito por Marx (1980), apesar de ser a jornada de trabalho uma grandeza variante, um campo de batalha constante entre patrão e empregado, o capitalista busca sempre prolongá-la ao máximo chegando, se possível, a transformar um dia de trabalho em dois. Quando as lutas dos trabalhadores alcançaram a redução da jornada de trabalho, o capital passou a investir no desenvolvimento da maquinaria, de maneira a capacitar o trabalhador a produzir mais num menor espaço

Olh@res, Guarulhos, v. 2, n. 2, p. 135-153. Dezembro, 2014. 
de tempo. Já naquela época, o autor frisa que esse mecanismo impõe ao trabalhador o aumento da tensão, o preenchimento mais denso da jornada e um grau maior de condensação do trabalho possível pela redução de sua duração. Portanto, apesar de diminuído o tempo oficial de trabalho diário, esse novo mecanismo de condensação do trabalho representa sua compensação através uma maior quantidade de trabalho concentrada em menor quantidade de tempo.

$\mathrm{O}$ autor, em sua obra, focaliza principalmente o trabalho material, que era a maioria quase absoluta em seu tempo. Mas isso não significa que esses mecanismos de condensação do trabalho se restrinjam especificamente à classe que produz mais valia.

Nesse ponto, Dal Rosso (2008) lembra que os tempos mudaram. Com o desenvolvimento tecnológico e de equipamentos de comunicação e armazenamento de informações, vem se ampliando cada vez mais o trabalho imaterial, concentrado principalmente no setor de serviços, mas presente mesmo entre os trabalhadores do setor industrial. Por isso, o autor ressalta que seria errôneo considerar que tal condensação do trabalho - chamada por Marx (1980) e também por ele, de intensificação - se restrinja ao trabalho industrial, já que os setores de trabalho imaterial, apesar de não se adequarem à noção de "tempo de trabalho socialmente necessário",

[...] situam-se entre aqueles que mais concentram capitais e, consequentemente, em que as formas de competição por resultados, por produtividade, por eficiência, adquirem contornos mais ferozes, tal como o caso de finanças, telefonia, comunicações, pesquisas, importações e exportações, não seria nada improvável pensar na hipótese de que o trabalho nesses setores pode estar sofrendo uma pressão ímpar por intensificação (DAL ROSSO, 2008, p. 34).

A pesquisa realizada por Dal Rosso (2008) deixou claro que os indicadores de intensificação estão presentes - em diferentes graus em todos os setores do trabalho contemporâneo, incluindo o de serviços públicos. Eles aparecem sob a forma de alongamento das jornadas, acúmulo de atividades, polivalência, ritmo e velocidade, e gestão por Olh@res, Guarulhos, v. 2, n. 2, p. 135-153. Dezembro, 2014. 
resultados (sejam eles de ordem quantitativa, no trabalho material; ou qualitativa, no trabalho imaterial).

Segundo o autor, os processos de intensificação tomam forma e se acumulam a cada vez que uma nova organização do trabalho se estabelece. Isso acontece sempre que as reivindicações e a crise põem fim a uma organização anterior, e uma nova estratégia que consiga, ao mesmo tempo, atender às reivindicações dos trabalhadores e aumentar o grau de intensidade do trabalho, se torna hegemônica; assim como foi com o toyotismo e sua forma de organização que já extrapolou há tempos o espaço das fábricas para influenciar a forma de trabalho nos mais variados setores.

Sempre que uma nova mudança na organização do trabalho acontece, geralmente com o acréscimo de mudanças tecnológicas, é necessário haver também uma mudança nas qualificações e conhecimentos dos trabalhadores, de maneira a adaptá-los à nova organização e às novas tecnologias (DAL ROSSO, 2008).

Quando pensamos no trabalho do gestor escolar ao longo das décadas, é inevitável perceber as novas configurações em seu trabalho e a presença de fatores de intensificação como o alongamento da jornada, o acúmulo de atividades e a gestão por resultados (PEREIRA; FIDALGO, 2013). E foi justamente para atender às demandas provocadas por tais configurações que o Curso de Especialização em Gestão Escolar foi desenvolvido para formar, em serviço, os gestores das escolas públicas brasileiras.

A formação, fornecida pelo governo federal e incentivada pelas secretarias estaduais e municipais de educação; as leituras e atividades do curso, que tratavam da realidade da escola e do papel do gestor frente às diversas demandas de seu trabalho na atualidade; o fato de estarem esses gestores, enquanto realizando as leituras e atividades do curso, pensando na escola onde trabalhavam e se qualificando para 
melhor exercer seu trabalho nela deixam clara a resposta às questões propostas acima.

Apesar de se inserir nos tempos dos gestores quando estes deixavam a escola após cumprir sua carga horária diária de trabalho, o curso poderia ser classificado também como um tempo de trabalho, se inserindo, portanto, como mais um instrumento de intensificação do trabalho do gestor, como fator de alongamento de sua jornada de trabalho.

Considerando a mediana de 10 horas semanais gastas com a realização do curso pelos sujeitos pesquisados, e a duração mínima de um ano de formação, chegar-se-ia a um total de 520 horas da expansão do tempo de trabalho desses gestores no ano da realização do curso; um total de 22 dias inteiros gastos ininterruptamente apenas com a realização do curso, ou de 65 dias a mais de trabalho naquele ano, se for considerada a jornada média de 8 horas.

Assim, é importante informar que $84 \%$ dos respondentes ao questionário afirmaram que o curso não atrapalhou seu trabalho na escola, e que nenhum deles considerou que a formação teria atrapalhado muito ou totalmente seu trabalho. Entretanto, quando responderam à questão relativa à sua rotina pessoal, foi possível perceber um aumento considerável das respostas indicando que a realização do curso teve consequências maiores sobre a vida pessoal dos gestores do que sobre seu trabalho $(60 \%$ dos respondentes afirmou que o curso atrapalhou, em alguma medida, sua rotina pessoal).

Apesar disso, é interessante perceber que, apesar de realizarem as atividades do curso em suas residências, no tempo que seria utilizado para seu descanso e lazer, $40 \%$ dos respondentes ainda assim não considerou que o curso atrapalhou sua rotina pessoal.

A explicação para o fato pôde ser encontrada nos relatos dados pelos sujeitos entrevistados, quando expunham o orgulho de terem a possibilidade de realizar um curso de especialização pela UFMG, bem Olh@res, Guarulhos, v. 2, n. 2, p. 135-153. Dezembro, 2014. 
como, em alguns deles, o prazer constante nos estudos. Relatos assim foram também encontrados na pesquisa de Gatti (2008), na qual a autora discute os programas públicos de formação de professores a distância e evidencia que tais iniciativas são muito valorizadas pelos profissionais da educação por motivos como a oferta gratuita, o material disponibilizado, os tutores, o contato com professores especialistas de grandes universidades e as oportunidades de troca com os pares; sendo que poucos participantes avaliaram os diversos programas estudados como muito ou totalmente negativos.

Outra hipótese nos é dada por Dal Rosso (2008, p. 198), quando argumenta que qualquer tipo de trabalho envolve, simultaneamente, a energia física, intelectual, emocional e relacional do trabalhador, sendo que, a depender do setor em que o trabalhador esteja inserido, ele irá utilizar predominantemente um desses componentes. No caso específico da educação e dos demais trabalhos ligados ao cuidado - que abarcam também a saúde, o tratamento de drogados e os setores de atendimento ao público como um todo - requerem altíssimas doses de envolvimento emocional, o que geralmente provoca uma carga de intensificação para dar conta da tarefa que muitas vezes não é considerada.

No caso do público pesquisado, foi possível perceber seu profundo envolvimento emocional com as escolas onde trabalham, bem como o sentimento de responsabilização que têm por elas. Em relatos vistos de participantes que viam a escola como sua própria casa; ou que iam às lágrimas pelo fato de sua escola não estar bem classificada na avaliação externa; ao receberem telefonemas pessoais, em casa nos finais de semana, para resolver problemas referentes à escola; na felicidade de relatar a melhoria nas condições da escola, etc (PEREIRA; FIDALGO, 2013). Foram infindáveis os relatos que mostraram o quanto esses gestores muitas vezes se confundem e já não conseguem ver onde termina seu trabalho como educadores e onde começa sua vida 
pessoal. Já estão tão acostumados em ter seu tempo "livre"/não-trabalho invadidos por seu trabalho na escola, que veem suas responsabilidades na escola como parte de sua rotina pessoal e, portanto, com o curso não seria diferente.

Além disso, é preciso lembrar que estamos presenciando o estabelecimento de uma ideologia que vai muito além dos setores de cuidado, e que se apresenta como essa sensação tida pelo trabalhador de que a formação continuada é sua responsabilidade e que, portanto, ele deve dispender sozinho dos custos e do tempo para a realização de tal preparação para o trabalho, como se fosse ele o único beneficiado por ela.

Ambos os sentimentos puderam ser vistos nos relatos dos sujeitos participantes da pesquisa, ao falarem da formação no curso quase que com medo de reclamarem dela, tentando amenizar as dificuldades encontradas através dos bons resultados alcançados na escola ou da sensação de estarem mais bem qualificados. Outro indício desse movimento ficou claro na naturalização com que esses profissionais tratavam todos os sacrifícios realizados em função da realização do curso (perda de eventos sociais, poucas horas de sono, reclamações dos familiares por sua ausência, etc.); e pôde se manifestar também em relação aos colegas de trabalho, na forma crítica como falavam daqueles que não se dispunham aos mesmos sacrifícios e optavam por não realizarem as formações; e no entendimento da formação como algo pessoal, sem relação com o trabalho ou o ambiente escolar.

Sendo assim, o envolvimento emocional característico da profissão, junto a essa culpabilização do trabalhador, atingem contornos cada vez maiores e os põem mais perto de aumentarem os sacrifícios já feitos do que de reivindicarem melhores condições de trabalho e formação. 
A situação torna-se ainda mais cruel nos novos desenhos das formações dos trabalhadores da educação utilizando a modalidade de Educação a Distância, já que esta possibilita um mascaramento maior das condições de formação, pois não existe uma carga horária diária pré-definida e, como ela se dá no ambiente doméstico, fica oculta e nebulosa muitas vezes para os próprios sujeitos.

Neste sentido, Branco (2008) - que encontrou em sua pesquisa infindáveis relatos de professores que alegavam a falta de tempo como principal fator dificultador para a realização da formação - argumenta que, apesar de a EaD (Educação a Distância) ter respaldo legal em sua utilização para formação de professores em serviço, é fundamental que sejam garantidas a eles também as condições históricas para a realização de suas formações, a saber, condições materiais e de tempo para a realização dos estudos.

Segundo Aguiar (2011, p. 77) a importância de se garantir condições objetivas para que os participantes do Curso de Especialização em Gestão Escolar pudessem realizar a formação é enfatizada em sua própria proposta pedagógica; levando-se em consideração as demandas de leituras, atividades e até mesmo trabalhos em grupo, a disponibilidade de tempo para dedicação ao curso é essencial. Porém, o autor argumenta que, entre os fatores que interferiram diretamente na implementação do curso, está a insuficiência do tempo disponível aos gestores para dedicação ao curso, já que "na maior parte das vezes, as secretarias de educação não os liberavam para realização dos estudos".

$\mathrm{O}$ artigo $67^{\circ}$ da LDB, que trata da valorização dos profissionais da educação, traz em seu inciso II a asseguração do "aperfeiçoamento profissional continuado, inclusive com licenciamento periódico remunerado para esse fim" (BRASIL, 1996, grifos nossos), porém esse permanece restrito ao texto da legislação para muitos dos profissionais da educação, incluindo grande parte dos gestores pesquisados, aliás, 
assim como as garantias dos demais incisos (PEREIRA; FIDALGO, 2013).

Entre os registros realizados ao longo da pesquisa, entre questionários e entrevistas, apenas um participante disse ter tido tempo disponibilizado, em sua carga horária de trabalho, para a realização do curso, além do aparato material básico para a realização do mesmo que, segundo o egresso, foi o fator determinante para que conseguisse finalizar o curso com sucesso.

Unem-se a isso a falta de progressão na carreira, de ajuda de custo para a participação nos encontros presenciais, a falta de condições materiais para a realização da formação continuada, e mais uma vez o "profissional" da educação - que não coincidentemente é majoritariamente composto por mulheres - leva trabalho para casa sem qualquer reconhecimento financeiro ou social, pelo simples amor à educação.

\section{Considerações finais}

É indiscutível a importância da formação continuada em função do constante avanço científico e tecnológico; sobretudo na educação, responsável por formar aqueles que irão lidar com tais avanços.

Entretanto, considerando o aumento vertiginoso das ofertas e demanda por formação continuada entre os profissionais da educação, várias delas inclusive fornecidas pelo poder público, torna-se cada vez mais necessário pensarmos para além da necessidade da formação, considerando também a forma como esta vem sendo realizada e se inserindo na vida do educador.

Foi percebido que a formação continuada acontece muitas vezes exclusivamente no "tempo livre" desse trabalhador, invadindo sua casa, seu descanso e lazer com as mudanças, demandas e problemas de seu ambiente de trabalho; forçando-o a criar estratégias educacionais Olh@res, Guarulhos, v. 2, n. 2, p. 135-153. Dezembro, 2014. 
enquanto cria seus filhos, a encontrar soluções de gestão enquanto tenta dormir. Pois caso não o faça, não será digno de seu salário, de seu trabalho, e será culpado por seu próprio desemprego.

E mais uma vez as tecnologias são facilitadoras da exploração e intensificação do trabalho, quando permitem que a formação continuada - e com ela o trabalho em si - invadam os lares do trabalhador, suas noites, seus finais de semana e férias.

A possibilidade de realizar a formação "quando" e "onde" quiser, oferecida pela Educação a Distância, coincidentemente se encaixou perfeitamente nos tempos e espaços "livres" de 96\% dos sujeitos pesquisados que realizaram o Curso de Especialização em Gestão Escolar, prolongando sua jornada de trabalho.

Apesar das facilidades proporcionadas pela educação a distância (expansão geográfica da oferta, flexibilidade, desnecessidade de deslocamento, etc.), o fato de possibilitar a realização da formação em suas casas, sem delimitação de carga horária diária, não diminui o esforço desprendido em leituras e atividades. Assim também como não impede a invasão do trabalho aos tempos livres/de não trabalho do educador, ao contrário, a torna ainda mais forte quando se faz em seu próprio local de descanso, dificultando ainda mais sua percepção dessa invasão; talvez até por já estarem eles tão habituados a ela.

Por fim, é importante frisar mais uma vez que não se objetivou, com o presente artigo, argumentar contra a formação continuada, ou questionar sua importância, que é fato inquestionável. Além disso, é necessário ressaltar mais uma vez que seu poder de alcance é multiplicado pelas ferramentas da educação a distância, tornando possível que as oportunidades de formação continuada não mais se restrinjam aos grandes centros, e possam alcançar também o interior, democratizando o acesso à formação. Entretanto, juntamente com a oferta e incentivo à formação continuada de professores e gestores, é preciso que haja um cuidado com suas implicações na vida desse 
Aline Gabriele Pereira \& Fernando Selmar Rocha Fidalgo

trabalhador já tão sofrido, e que a ele sejam dadas condições objetivas para a realização da formação sem o comprometimento de sua vida pessoal, sem que precise se sacrificar ainda mais por uma educação de qualidade.

Olh@res, Guarulhos, v. 2, n. 2, p. 135-153. Dezembro, 2014. 


\section{Referências}

AGUIAR, M. A. S. Formação em gestão escolar no Brasil nos anos 2000: políticas e práticas. Revista Brasileira de Política e Administração da Educação, v. 27, n. 1, p. 67-82, 2011.

ALBERTO, M. A. A noção de empregabilidade nas políticas de qualificação e educação profissional no Brasil nos anos 1990. Trabalho, Educação e Saúde, Rio de janeiro, v. 3, p. 295-330, 2005. Disponível em http://www.scielo.br/scielo.php?script=sci arttext\&pid=S1981-77462005000200004, acesso em 23/05/2014.

ANTUNES, R.Os sentidos do trabalho: ensaio sobre a afirmação e a negação do trabalho. $2^{\text {a }}$. ed. São Paulo: Boitempo Editorial, 2009. v. 1. p.287.

BRANCO, J. C. S. A educação a distância para o professor em serviço. 2008. Dissertação (Mestrado em Educação Tecnológica) - Centro Federal de Educação Tecnológica de Minas Gerais, Belo Horizonte, 2008. Disponível em http://www.dominiopublico.gov.br/pesquisa/DetalheObraForm.do? select action=\&co ob $\underline{\mathrm{ra}=156516}$, acesso em 23/05/2014.

BRASIL. Lei de Diretrizes e Bases da Educação Nacional, Lei 9394 de 20 de dezembro de 1996. Estabelece as diretrizes e bases da educação nacional, 1996. Disponível em http://portal.mec.gov.br/arquivos/pdf/ldb.pdf, acesso em 23/05/2014.

DAL ROSSO, S. Tempo de trabalho. In: CATTANI, A. D.; HOLZMANN, L. (Org.). Dicionário de Trabalho e Tecnologia. Porto Alegre: Editora Zouk, 2011.

DAL ROSSO, S. Mais trabalho! A intensificação do trabalho na sociedade contemporânea. São Paulo: Boitempo Editorial, 2008. v. 1. 190p.

FIDALGO, N. L. R.; ARANHA, A. V. S. A espetacularização do trabalho docente universitário: dilemas entre produzir e viver e viver para produzir. 2010. 200 f., Tese (doutorado) - Universidade Federal de Minas Gerais, Faculdade de Educação. Disponível em http://www.bibliotecadigital.ufmg.br/dspace/handle/1843/HJPB-858P3S, acesso em 23/05/2014.

GATTI, B. A. Análise das Políticas Públicas para formação continuada no Brasil, na última década. Revista Brasileira de Educação, v. 13, p. 57-70, 2008. Disponível em http://www.scielo.br/pdf/rbedu/v13n37/06.pdf, acesso em 23/05/2014. Olh@res, Guarulhos, v. 2, n. 2, p. 135-153. Dezembro, 2014. 
HARVEY, D. Condição pós-moderna: uma pesquisa sobre as origens da mudança social. 22a edição, São Paulo: Edições Loyola, 2012.

KENSKI, V. M. Novas tecnologias, o redimensionamento do espaço e do tempo e os impactos no trabalho docente. Revista Brasileira de Educação, São Paulo, 1998. Disponível em http://educa.fcc.org.br/pdf/rbedu/n08/n08a06.pdf, acesso em 23/05/2014.

MARX, K. O capital: critica da economia politica. 6. ed. Rio de Janeiro: Civilização Brasileira, v.1, 1980.

PEREIRA, A. G.; FIDALGO, F. S. R. Os tempos e espaços do gestor escolar em formação na educação a distância. 2013. 164 f., Dissertação (mestrado) - Universidade Federal de Minas Gerais, Faculdade de Educação. Disponível em http://www.bibliotecadigital.ufmg.br/dspace/handle/1843/BUBD-9EFLRB, acesso em 23/05/2014.

ROSENFIELD, C.L.; NARDI, H.C. Competência. In: Cattani A.D., Holzmann L. Dicionário de Trabalho e Tecnologia. Porto Alegre (RS): Editora UFRGS; 2006 p. 62 65. 